\title{
XL. The Simmance-Abady "flicker" photometer
}

\section{Messr. Simmance \& Messr. Abady}

To cite this article: Messr. Simmance \& Messr. Abady (1904) XL. The SimmanceAbady "flicker" photometer, Philosophical Magazine Series 6, 7:40, 341-346, DOI: 10.1080/14786440409463125

To link to this article: http://dx.doi.org/10.1080/14786440409463125

$$
\text { 曲 Published online: } 15 \text { Apr } 2009 .
$$

Submit your article to this journal $\pi$

Џ Article views: 3

Q View related articles 두 
thus found; instead, we multiply $-u^{\prime}$ (in motion harmonically periodic) by the electric force corresponding to the displacement thus found, that is by $4 \pi \mathrm{V}^{2}$ times the displacement, or by $-4 \pi i \mathrm{~V} / \kappa$ times the velocity ( $e^{i \kappa \mathrm{V} t}$ being the time factor). Thus in applying (33) to an electric problem $\mathbf{F}^{\prime}$ is to be replaced by $-u^{\prime}$, and $\mathrm{F}$ by $-4 \pi i \mathrm{~V} / \kappa \cdot(-d u / d t)$ or $-4 \pi \mathrm{V}^{2} u$; when this is done in the present case all the results agree.

9. I would take this opportunity of correcting the following error in my former paper * :-p. 671, line 4 from foot, delete "slowest constituent" and for "small " read "large."

\section{The Simmance-Abady "Flicker" Photometer. By Messrs. Simmance \& Abady $†$.}

\section{[Plate XX.]}

THIS photoneter is of the alternating-light type, recently 1 called in France "scintillation-photometer," but more generally known in America and England as "flicker."

A very long experience with all the known variations of "flicker" photometers, and the construction of many others of different patterns, resulted in the design of the present instrument, and enabled actual rules to be laid down, which when adhered to produce a photometer which is most sensitive to degrees of lights of the same colour, and also enable the intensities of the most violently contrasted tints to be compared and balanced.

These rules are as follows:-The light effects must be in juxtaposition without any apparent division line, and must move, oscillate, or rotate so that the point of juncture of the rays of the two lights passes and returns entirely across the vision-field. Any hiatus, or longer exhibition of one light than the other, biases the result. The observation surface or surfaces upon which the light rays fall, must be at exactly the same distance from the eye, at exactly the same angle in relation to the line of sight, and must be of pure white such as is afforded, for example, by a clean chalk, plaster of Paris, magnesium carbonate, or barium sulphate ; any tint affects the accuracy of the result. The observation surfaces must also themselves in turn occupy the field of vision; an apparent movement or optical illusion does not afford accurate results.

Sir W. Abney, whose work in colour photometry is so well known, has placed on record his opinion that in using the

* Phil. Mag. Dec, 1903.

+ Communicated by the Physical Society : read December 11, 1903. 
"flicker" photometer, the operator was in some way testing acuteness of sight, and not relative intensities. Acuteness of sight naturally does come into play in this, as in all other matters in which sight is used at all, but when we remember that with lights of the same tint we apparently see in the photometer a white surface which is alternately illuminated by the two lights, we must conclude that when this alternation is invisible (that is to say, when we can see no change) the reason is because both lights are of the same power. Naturally, abnormally acute vision would perceive more minute changes of intensity, but this is a factor always present in any investigation of the sort.

It appears quite certain that the relative intensities of two lights, whether of the same colour or different, can be accurately and easily gauged by the method. An interesting experiment has recently been conducted by $\mathrm{Mr}$. Roxburgh and Mr. Young, of the Ophthalmic Hospital. Readings upon this photometer were made independently by, firstly, Mr. Jacques Abady, who is an experienced photometrist, but suffering from astigmatism; secondly, a gentleman with a pupil dilated by treatment with atropin ; thirdly, a patient from the hespital, absolutely colour-blind; and, fourthly, by the writer, whose sight is considerably impaired, but who has some experience with photometer reading. All the results coincided, and this not only when the lights were of the same white tint, but with red against white, green against white, and green against red. A test of very dark blue against red showed slight discrepancies, owing, probably, to the great obscuration of the light by the blue, almost black, glass, but even these were no more in importance than would probably have occurred when using a Lummer-Brodhun or Bunsen disk with lights of the same colour.

The method of reading with this photometer resolves itself into the simple question as to whether the disk of light seen through the sighting tabe is moving or is motionless. An observer who makes a reading for the first time, when he fully understands that he is required to do no more than this, can read with as great facility and accuracy as an experienced operator, and it is this facility which gives value to an apparatus intended for testing the high intensity lights in vogue at the present time, and also colour effects.

As to the causes of the phenomenon, they, no doubt, are simple on the surface, but may be more complex when closely considered. The pupil of the eye cannot adjust itself to the rapidly changing intensities, and when the balance is struck, the light, being unchanging and motionless, permits of pupil 
adjustment. The colours then blend by persistence of the impression, but should the intensities again change, this retentive sense is dulled by the anxiety of the nerves controlling the pupil orifice to perform their work, an endeavour, however, frustrated by the rapid changing. It appears certain that an abnormal excitation of the nerves controlling the diaphragm has the effect of lessening the susceptibility of the retina to retention of impressions, whether this excitation is caused by glancing at a bright light or by gazing too long at the changing disk of the photometer. When the nerves are over-strained in this way the "flicker" does not disappear at all in many cases, although the point of equality of intensity is always unmistakable. Thus in using the photometer it is suggested that the instrument shall be moved along the bar rather rapidly, the while observing the disk through the sighting-glass. The "motionless" point will then be apparent at once, and by a little practice (which in this, like everything else, generates confidence) an operator will swing the disk-box into its balance of intensity without an effort and without giving the sensitiveness of his retina time to suffer from the numbing effect of the flickerings or throbbing. These conditions point to the possibility of the eyes becoming under other circumstances of stress unable to appreciate the disappearance of the flicker. Obviously, if fatigue can produce such effects as described, certain conditions of health will act similarly. It may be that a bad liver will produce a constant flicker effect; it is quite certain, however, that no circumstances short of partial or absolute blindness can prevent the point of equality of intensity being appreciated, although it may evidence itself in different appearances of the disk according to the varying conditions of the retina as mentioned above.

The writer would submit, with all deference to the expressed opinions of many of the world's greatest scientists, that the Purkinje phenomenon does not affect the accurate working of the form of Flicker photometer shown, if indeed it affects any form of alternating photometer. This Purkinje effect may be briefly described in this way :-A right-angled wedge receives upon one face the reddish light from a pentane standard, and on the other the bluish light from an arelamp-we then adjust the relative positions of the arc-lamp, the pentane standard, and the wedge until we obtain what we consider is an equal illumination on the two adjacent sides of the wedge. If we then move in both these lights to half their distance from the wedge, we find that the retiual stimulation or apparent brightness of the two surfaces is no 
longer the same. It is quite clear from this (and also we may gather the cause from Fechner's law and Von Helmholtz) that the retinal sensation of brightness does not increase according to the same law for all colours. It is obvious, therefore, that no unaided eye can judge accurately in photometrical comparisons so long as the disturbing effect of colour is present, unless the distances between the receiving surfaces and the lights are arranged according to some rule which must take the place of that of inverse squares. To put this in another way, it follows that even though an expert photometrist can with a Bunsen or LummerBrodhun apparatus arrive at what he is certain is (and what is no doubt) a fair balance of the two tints he is comparing, yet grave doubts must exist as to whether the relative candlepowers of the two sources can be taken as being indicated by this balance. The Purkinje effect is purely a colour effect and colour does not enter into consideration in this "Flicker" photometer.

No one would dream of considering a colour-blind person to be affected by the Purkinje law, and yet, as has been shown, sucb a person can read accurately with this photometer. The experiments inade to prove the Purkinje phenomenon have all been carried out with coloured surfaces, never, so far as is generally known, with a scintillation photometer, but conclusive trials have shown that with this instrument as now shown, no alterations in distance disturb the true readings. A red light compared with a green at 3 metres gives the same comparative intensities to each as at 2 metres, and an arc-light tested against a 10 -candle pentane lamp at 40 feet indicates the same candle-power as when the distances are reduced to 15 feet. Thus the question of colour does not interfere with the results.

The accuracy of the photometer for coloured lights is confirmed by the following experiments.

Two standard lamps of exactly the same power were used, one at each end of the photometer-bar. A coloured glass screen was interposed, to intercept the rays from one light, which was then measured against the unscreened light. 'This gave value for one coloured screen. A second colour was then substituted for the first and its value measured against the same unscreened light. Thus the following values were obtained :-

(a) Unscreened lights.

(b) Candle-power of one light screened with one colour.

(c) Candle-power of one light screened with the other colour. 
It is obvious, therefore, that one obtained the theoretical ratios of the one light screened with the first colour in terms of the other light screened with the second colour. Then the one colour was compared against the other, and the results show how nearly this ratio agrees with the theoretical ratios. Various initial powers of lights and various lengths of bars were used for these experiments. All the readings on the bar were computed according to the law of inverse squares; and it was therefore assumed that the absence of "flicker" or point of equality indicated by the Simmance-Abady photometer is candle-power of intensity of light.

The following tests are the mean of three persons' readings, and the three individual readings all made independently showed practically no variations.

\begin{tabular}{|c|c|c|c|}
\hline & $\begin{array}{l}\text { Power in } \\
\text { Candles. }\end{array}$ & $\begin{array}{c}\text { Theoretical Ratio. } \\
\left(\begin{array}{l}\delta \\
\theta\end{array}\right) .\end{array}$ & $\begin{array}{l}\text { Actual Reading } \\
\text { on Photometer. }\end{array}$ \\
\hline $\begin{array}{l}\text { Signal Green } \ldots . . .8 \\
\text { Sigual Red........ }\end{array}$ & $\left.\begin{array}{l}21 \cdot 8 \\
156\end{array}\right\}$ & 1.4 nearly & $1 \cdot 39$ \\
\hline $\begin{array}{l}\text { Yellow } \ldots \ldots \ldots \ldots \delta \\
\text { Blue } \ldots \ldots \ldots \ldots \ldots \theta\end{array}$ & $\left.\begin{array}{l}9 \cdot 75 \\
2 \cdot 088\end{array}\right\}$ & $4 \cdot 67$ & 475 \\
\hline $\begin{array}{l}\text { Yellow } \ldots \ldots \ldots \ldots . \delta \\
\text { Red................ }\end{array}$ & $\left.\begin{array}{r}10 \cdot 01 \\
1.45\end{array}\right\}$ & $6 \cdot 9$ & $6 \cdot 86$ \\
\hline $\begin{array}{l}\text { Green............. } \delta \\
\text { Blue... ......... } \theta\end{array}$ & $\left.\begin{array}{l}2 \cdot 16 \\
2 \cdot 0\end{array}\right\}$ & 1.08 & $1 \cdot 08$ \\
\hline $\begin{array}{l}\text { Purple } \ldots \ldots \ldots \ldots . . \ldots \\
\text { Red................ }\end{array}$ & $\left.\begin{array}{l}2 \cdot 0 \\
1.55\end{array}\right\}$ & $1 \cdot 29$ & $1 \cdot 275$ \\
\hline$\underset{\text { Signal Green....... }}{\text { Purple }}$ & $\left.\begin{array}{l}3 \cdot 81 \\
2 \cdot 0\end{array}\right\}$ & 1.95 & 1.9 \\
\hline
\end{tabular}

To detail briefly the construction of this Simmance-Abady photometer :-It consists of a wheel of a white material (Pl. XX. fig. 1) with a specially shaped periphery, which wheel is caused to revolve before an eyepiece by means of a suitable motor. At right angles to the line of sight and parallel with the axis of the revolving wheel are the two lights undergoing examination, the rays of which fall upon the shaped periphery of the wheel, enabling the effect of each light to be seen in turn through the eyepiece.

Pl. XX. fig. 2 shows the four cardinal positions of the wheel in sequence, illuminated by two unequal lights. It will be seen how the light effects travel across the line of vision and alternate as the wheel revolves. 
The revolving wheel has its periphery formed by two equal conical surfaces or other surfaces of revolution. The axes of the two conical surfaces are each parallel to the axis of the revolving wheel, at exactly equal distances therefrom, and the three axes lie in the same plane. The vertices of the conical surfaces are at equal distances on opposite sides of the line of sight. In manufacturing, the wheel is first made as a disk of uniform thickness. It is then chucked in a lathe eccentrically, and a straight line motion being given to the cutting or grinding tool, the conical surfaces are generated. The wheel is then rechucked eccentrically on the opposite side, and the other conical surface is generated by the cutting or grinding tool, having the same straight line motion as before. The result is that the periphery of the wheel has its two sides uniformly sloping at equal opposite angles, while the ridge of intersection of the two surfaces crosses and recrosses the axis of vision during each revolution. This wheel is driven with a motion communicated from a suitable motor, either spring, electric, or any form which will produce absolutely regular motion-and at the same time afford means for easily adjusting the speed. In the instrument shown an expansion governor is utilized driven at a carefully arranged ratio speed, but the connexion between the spindle carrying the governor and that carrying the reflecting wheel is not rigid, but effected by means of a coiled spring. The most perfect accuracy of centreing is essential. Ontside the box are the remontoir, stopping, and starting lever, and speed adjustment, a spring motor being used.

The peculiar shape of the reflecting-wheel affords means for using it in manners quite impossible in any other form of colour photometer, that is to say, it may, at will, test lights at various angles from the horizontal. Having found the careful cutting of the angles of the wheel so vital it necessarily follows that when lights out of the horizontal are being tested, the box containing the wheel must be just as carefully turned on its axis for preserving the arranged conditions. A double quadrant scale (one scale being numbered at double the actual angle) and a small sighting or view-finding attachment enable the angle formed by the horizontal of the one light and the altitude of the other to be accurately ascertained, and the box to be placed at the correct angle of bisection.

The photometer is made to suit any bar or scale. The standards of dimensions are those of the Lummer-Brodhun apparatus and the ordinary Bunsen disk-box. 
Phil. Mag. Ser. 6, Vol. 7, PI. XX.

Fra. 1.

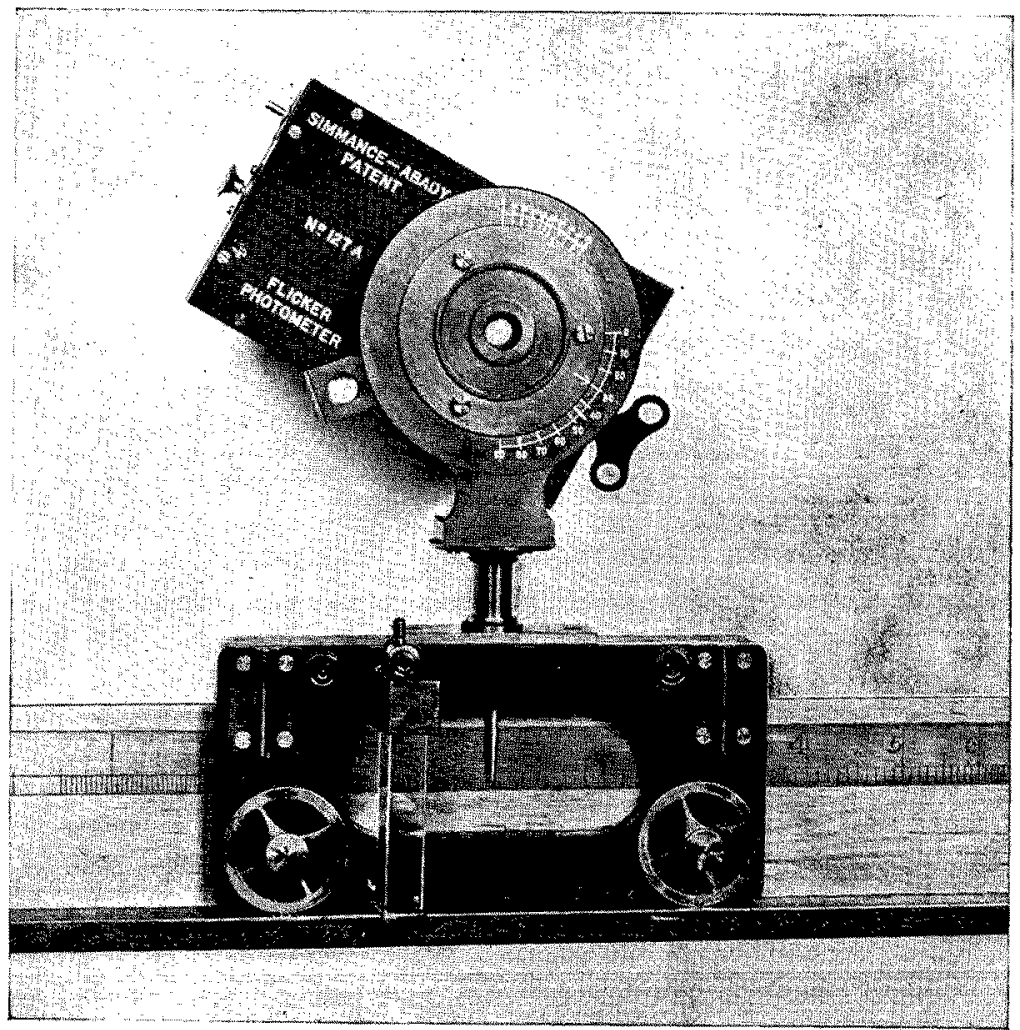

SIMMANCE-ABADY PHOTOMETER (Angle-form)

Frg. 2.

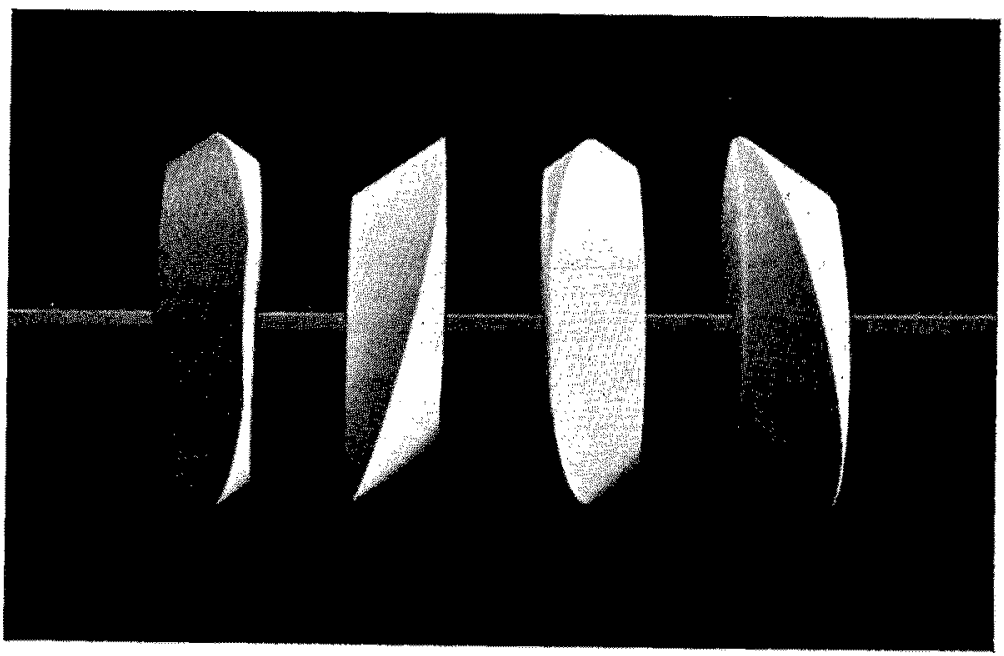

